\title{
Pablo Macera en la memoria
}

Era la tarde del 9 de enero de 2020 y la noticia corrió por los teléfonos y las redes sociales. Pablo Macera ya caminaba entre los seres mágicos andinos y amazónicos, se confundía con los sabios de tiempos ancestrales y conocía por fin el verdadero rostro del rebelde Túpac Amaru.

El historiador huachano surcó por los afluentes de la historia social, económica, política y cultural, y se internó en recónditas e ignoradas manifestaciones de arte popular. Su ingente legado intelectual, compone un corpus académico y estético que aprenderemos a aquilatar conforme asumamos que ya no está entre nosotros.

Vuelvo a mirar la estremecedora portada de su libro escolar para segundo año de secundaria, y entiendo por qué escogí los murales de Huaro para mi tesis de licenciatura. Y recuerdo las conversaciones con el maestro, como aquella mañana en la que hablábamos de la enrevesada problemática nacional. De pronto cortó la conversación y se retiró, cuando trataba de despedirme se volvió y me dijo: «Esto no es un país ... no sé qué es ... pero no es un país» (figura 1). Y se fue. Me quedé parado y desconcertado pensando en esas palabras. Y es que un verdadero maestro no tiene todas las respuestas, pero es capaz de despertar en sus oyentes la inquietud abrasadora de repensar los temas capitales. Aún no puedo explicar qué es el Perú, pero gracias a esa saeta clavada en mi ser, he tratado de entender un poco más la grandeza y tragedia de mi país.

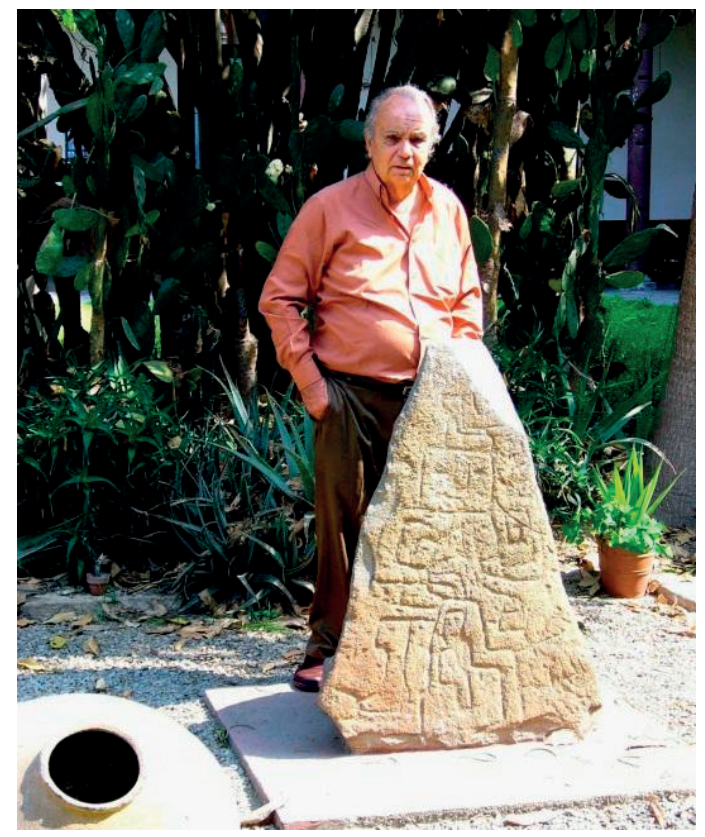

Figura 1. Retrato de Pablo Macera en el Colegio Real. (Década de 2000). Fotografía: Virgilio Cabanillas.

(C) Los autores. Este artículo es publicado por ISHRA, Revista del Instituto Seminario de Historia Rural Andina de la Facultad de Ciencias Sociales de la Universidad Nacional Mayor de San Marcos. Este es un artículo de acceso abierto, distribuido bajo los términos de la licencia Creative Commons Atribución 4.0 Internacional (CC BY 4.0) [https://creativecommons.org/licenses/by/4.0/deed.es] que permite el uso, distribución y reproducción en cualquier medio, siempre que la obra original sea debidamente citada de su fuente original. 
Sigue grabada en mi memoria la tarde en la que conocí su colección de arte popular. Un museo de objetos entendidos desde la perspectiva del arte como un hecho social. Caminamos entre piezas que habían arribado desde todos los rincones del país y al llegar a la vitrina de los amaru-tejas, observé estupefacto esas formas extrañas de animales híbridos — toros, felinos, reptiles - con restos de líquenes y los ojitos resaltados por piedrecitas brillantes. Cuál habrá sido la expresión de mi rostro, que el maestro me miró entusiasta y compartió lo que sentía: «Estos son dioses!». Efectivamente, estábamos mirando algo más que que viejas figuras de algún lugar de la sierra peruana. Esas obras de arte tradicional condensaban en su contenido formal e iconográfico, varias capas de una ancestral cosmovisión persistente en el tiempo. Y yo tenía el privilegio de verlas de cerca.

Este recuerdo me lleva a otro. Una mañana del año 2007 el colega Juan San Martín y yo entrevistamos al doctor acerca de su vocación y trayectoria profesional. Nos hablaba de las dificultades afrontadas y las numerosas decepciones. Cuando le preguntamos por alguna satisfacción personal que hubiera obtenido de la Historia, nos dijo:

Las satisfacciones de los descubrimientos —en ese instante se le iluminó el rostro - no solamente los descubrimientos documentales, sino de pronto cuando usted entiende una situación histórica pasada casi como por efecto de una revelación, que no es una revelación sino el resultado de la acumulación de aproximaciones y de equivocaciones, hasta que de pronto uno entiende lo que ha venido ocurriendo. Me ha pasado con el Amaru, por ejemplo.

En el 2005 curamos la muestra Bestiario de los Andes, en el Museo de Arqueología y Antropología de la UNMSM. Dicha exposición contó con una notable contribución en el notable prólogo que el Dr. Pablo Macera preparó para el catálogo. Fue una profunda reflexión sobre la representación de la fauna en el arte andino, desde el Lítico hasta la Conquista. Además, volvió a poner en la palestra dos excepcionales piezas de transición: un ceramio escultórico que representa un caballo, salido de las manos de un artista chimú y un mate decorado con una escena de la conquista, una batalla en la que los indígenas de la resistencia enfrentan a los españoles, sus indígenas auxiliares y perros de combate. Incluso detectó la presencia de un posible proto amaru en un cántaro zoomorfo de la cultura Recuay (figura 2). Un monstruo mítico con cabeza expresionista, ojos en alto relieve, fosas nasales bien pronunciadas y la gran boca abierta mostrando 29 dientes y 8 colmillos. Con apéndices sobre la cabeza, colocados de tal manera que configuran un par de orejas-asas. Esta pieza -que a nuestro entender combina elementos de felino y de zorro- procede de la Plaza Circular del Templo Temprano de Chavín de Huántar.

Ya sabemos que el doctor anduvo tras la pista del amaru, en todos los sentidos de la palabra y el concepto. En su artículo «El Amaru-teja, nueva ascensión de un dios andino» (1999), lo consideró uno de los centros de estructuración simbólica de la cultura andina. Postura coincidente con la de Francisco Stastny, otro gigante de las investigaciones en arte peruano.

En mayo del 2017, la Casona de San Marcos fue escenario de una muestra inesperada, cuando Israel Tolentino (ganador de premios como la Medalla de Plata de su promoción en la Escuela de Bellas Artes, XXVIII Salón Nacional de Grabado del ICPNA y Concurso Nacional de Pintura del BCRP), llevó las investigaciones del doctor Macera a una propuesta artística (figura 3). En este encuentro entre academia y artes plásticas, se dieron cita los pintores «primitivos» andinos, el rostro elusivo de Túpac Amaru, las serpientes míticas y las illas contemporáneas. El celebrado historiador fue el invitado de honor en la inauguración de la muestra titulada Waqaypata. Homenaje a Pablo Macera. 


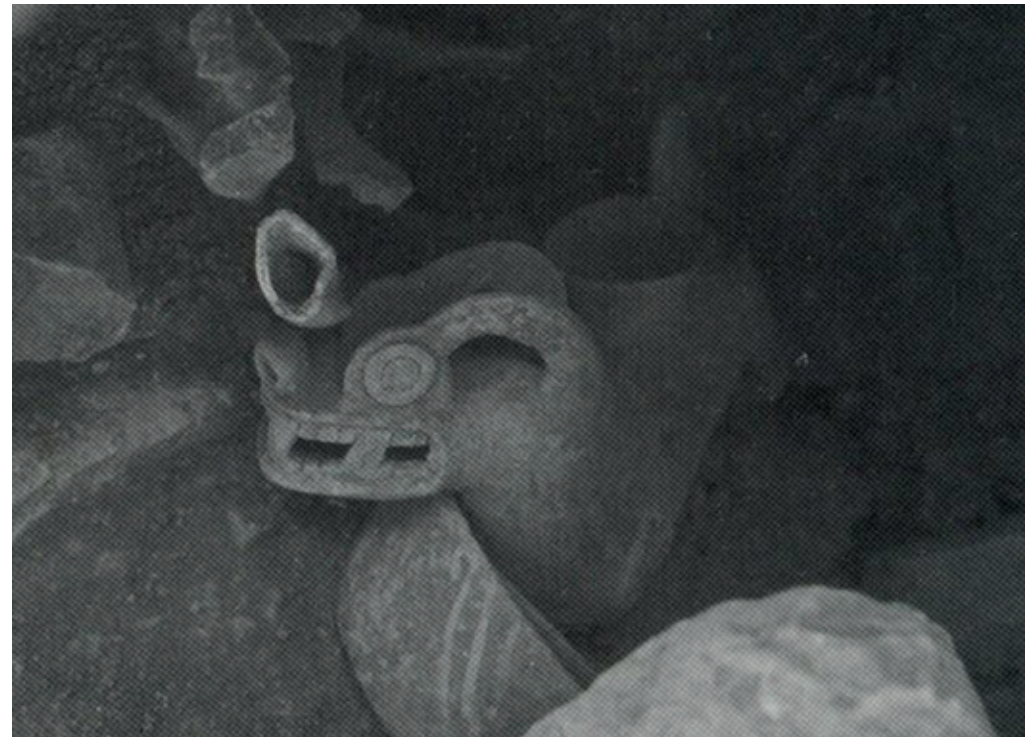

Figura 2. Hallazgo del ceramio durante las excavaciones organizadas por la UNMSM. (1970). Fotografía: Archivo del Museo de Arqueología y Antropología- UNMSM.

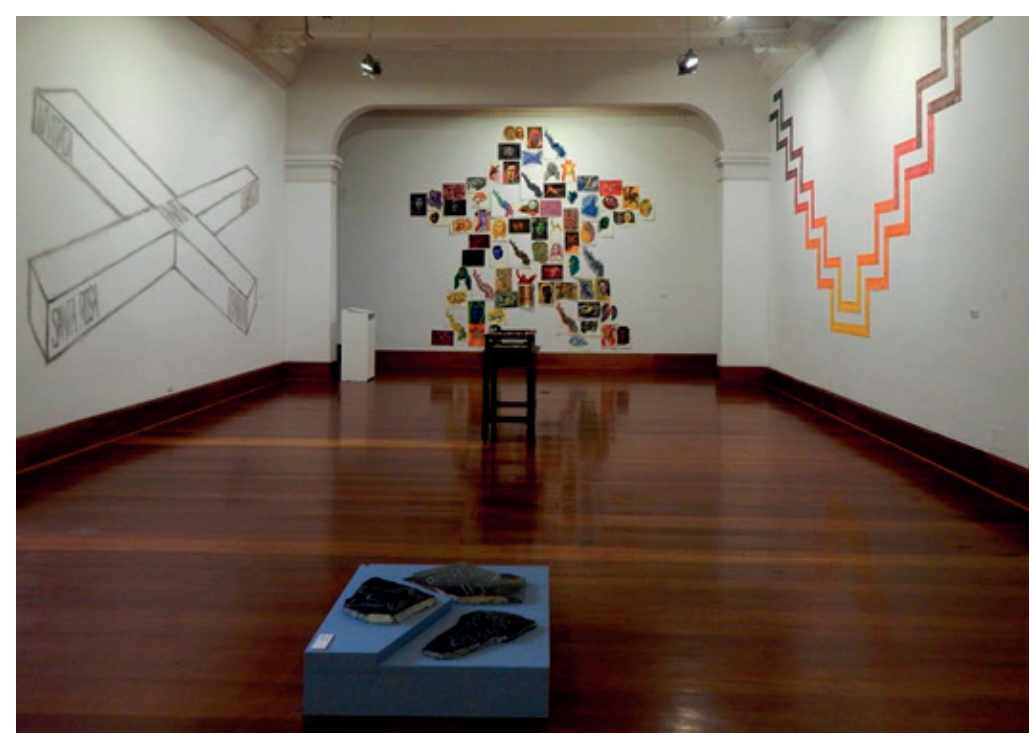

Figura 3. Vista de la muestra Waqaypata. Homenaje a Pablo Macera, en la sala Víctor Humareda del Centro Cultural San Marcos (2017). Fotografía: Virgilio Cabanillas.

Aquel luctuoso 9 de enero de 2020 el Perú perdió a uno de sus últimos sabios. El hombre que hablaba de historia, arqueología, sociología, arte, economía, etc. con la solvencia de un enciclopedista. Y que sabía valorar tanto las frías cifras de un documento estadístico como la belleza escondida en el dibujo de un jovencito desconocido.

En medio de la pena, es bueno saber que hay un proyecto de restauración para el Colegio Real, monumento histórico en el que Pablo Macera pasó gran parte de su vida. En dicho proyecto hemos planteado que el ambiente que acogió al doctor -al lado de la oficina del ISHRA- (figura 4), se convierta en una sala de exposición permanente dedicada a su invalorable obra. 


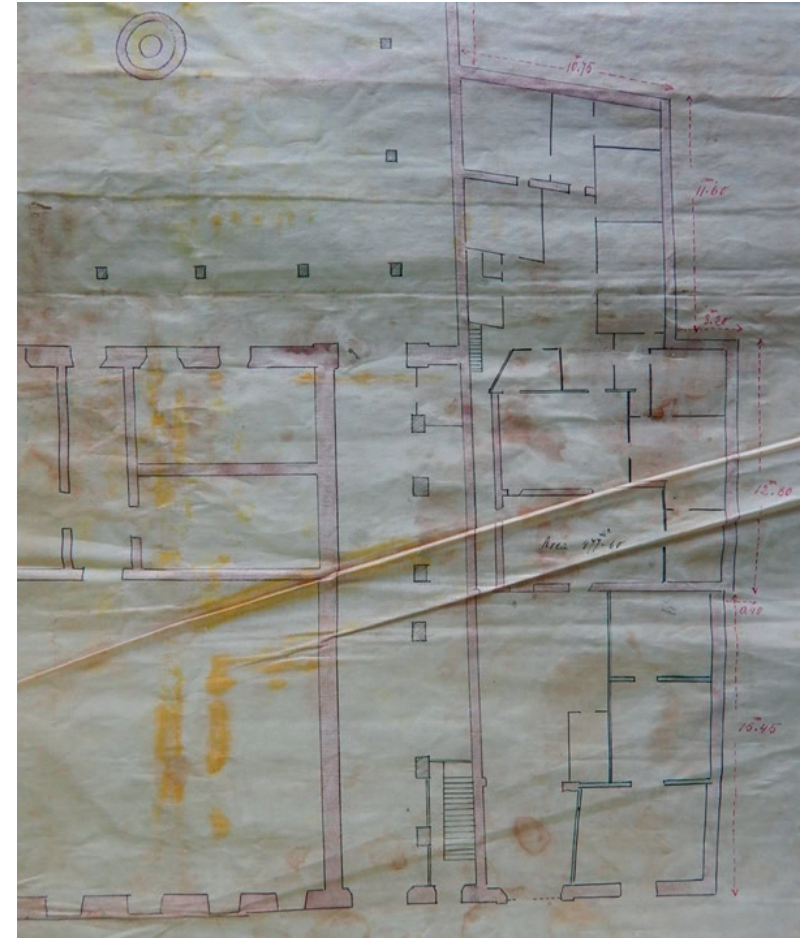

Figura 4. Castañón. (1897). Plano del Colegio Real (Detalle: Al centro se visualiza el sector en el que tenía su oficina el Dr. Pablo Macera. Se sugiere que ese ambiente se dedique a una muestra permanente de su aporte a la historia nacional). Fotografía: Archivo Histórico Domingo Angulo (UNMSM).

\section{Virgilio Freddy Cabanillas Delgadillo}

vcabanillasd@unmsm.edu.pe

Universidad Nacional Mayor de San Marcos

Publicado online: 27/12/2021 